Southern Illinois University Carbondale

OpenSIUC

Publications

Fisheries and Illinois Aquaculture Center

$10-2009$

\title{
Saturated Lipid Sources in Feeds for Sunshine Bass: Alterations in Production Performance and Tissue Fatty Acid Composition
}

Jesse T. Trushenski

Southern Illinois University Carbondale

Follow this and additional works at: http://opensiuc.lib.siu.edu/fiaq_pubs

(c) by the American Fisheries Society 2009

Published in North American Journal of Aquaculture, Vol. 71, Issue 4 (October 2009) at doi: 10.1577/

A09-001.1

\section{Recommended Citation}

Trushenski, Jesse T. "Saturated Lipid Sources in Feeds for Sunshine Bass: Alterations in Production Performance and Tissue Fatty Acid Composition." (Oct 2009).

This Article is brought to you for free and open access by the Fisheries and Illinois Aquaculture Center at OpenSIUC. It has been accepted for inclusion in Publications by an authorized administrator of OpenSIUC. For more information, please contact opensiuc@lib.siu.edu. 


\title{
Saturated Lipid Sources in Feeds for Sunshine Bass: Alterations in Production Performance and Tissue Fatty Acid Composition
}

\author{
Jesse T. TRUSHENSKI* \\ Fisheries and Illinois Aquaculture Center and Department of Zoology, \\ Southern Illinois University-Carbondale, Carbondale, Illinois 62901-6511 USA
}

\begin{abstract}
Feeds rich in saturated (SFAs) and monounsaturated fatty acids (MUFA) appear to maximize the retention of long-chain polyunsaturated fatty acids (LC-PUFA) in the fillets of sunshine bass (female white bass Morone chrysops $\times$ male striped bass $M$. saxatilis). To determine whether different sources of SFA and MUFA have equivalent effects on tissue fatty acid (FA) profile change, coconut (CO) and palm oils(PO) were evaluated as partial and complete substitutes for fish oil (FO) in feeds for juvenile sunshine bass. After 8 weeks of culture, the production performance of all groups was within the acceptable range for sunshine bass; however, weight gain was significantly reduced within the $100 \%$-CO group. Partial replacement of FO with $\mathrm{CO}$ or PO resulted in significant alteration of fillet FA profiles, and these changes were exacerbated in the complete-FO-replacement groups. The LC-PUFA were disproportionately enriched in the fillets of fish fed the reduced or FO-free feeds, whereas dietary surpluses of 12:0 and 14:0 (CO-based feeds) and 16:0 (PO-based feeds) were not reflected in any of the tissues analyzed. Rather, the levels of the SFA elongation-desaturation products (i.e., 18:0 and 18:1[n-9]) were elevated, particularly within liver lipid, suggesting enhanced FA biotransformation activity among fish fed higher levels of either alternative lipid source. Based on tissue FA composition, PO and CO appear to be approximately equivalent in terms of fillet LC-PUFA retention. However, the digestibility and utilization of these feedstuffs must be further investigated to maximize the ability of PO and CO to (partially or completely) replace FO in sunshine bass feeds.
\end{abstract}

To sustain long-term growth in the aquafeed and aquaculture industries, development and application of reduced or fish oil (FO)-free feed formulations is needed. Although use of plant- and terrestrial animalderived lipids is attractive in terms of reducing the economic and environmental costs of aquafeeds, replacing FO with alternative lipid sources reduces long-chain polyunsaturated fatty acid (LC-PUFA) content of the feeds. Because fish tissues respond in a time-dependent manner to changes in fatty acid (FA) intake (Jobling 2003, 2004a, 2004b; Robin et al. 2003), FO replacement reduces deposition of these functional nutrients within the resultant fillets.

Retention of LC-PUFA within the fillet lipid can be influenced by the FA composition of the feed used during grow-out (Trushenski et al. 2008a, 2009). Specifically, LC-PUFA retention is greater among fish raised on feeds high in saturated (SFA; degree of unsaturation $=0$ ) and monounsaturated FAs (MUFA; degree of unsaturation $=1$ ) compared with those fed medium-chain polyunsaturated FAs (MC-PUFA; chain length $=18$ carbon atoms, degree of unsaturation $\geq 2$ ). However, it is unclear whether different sources of dietary SFA and MUFA are equivalent in this respect.

\footnotetext{
* E-mail: saluski@siu.edu
}

Received January 8, 2009; accepted March 22, 2009 Published online September 3, 2009
To address whether specific composition of SFA- and MUFA-rich lipids influences tissue fatty acid (FA) profile change, I evaluated partial and complete replacement of FO with coconut oil (CO) and palm oil (PO) in feeds for juvenile sunshine bass (female white bass Morone chrysops $\times$ male striped bass $M$. saxatilis).

\section{Feeds and feeding trial.-A practical sunshine bass} feed (Table 1), including $200 \mathrm{~g} / \mathrm{kg}$ (dry matter basis) menhaden meal (Special Select, Omega Protein, Inc., Houston, Texas) and $98 \mathrm{~g} / \mathrm{kg}$ menhaden fish oil $(100 \%$ FO, Virginia Gold, Omega Protein, Inc., Houston, Texas), served as the control dietary formulation in the present work. Four experimental feeds were derived from the basal formulation, with $50 \%$ or $100 \%$ of the FO replaced with PO (50\% PO, 100\% PO; Jungle Products, Edison, New Jersey) or CO (50\% CO, $100 \%$ CO; Spectrum Organic Products, Petaluma, California). All feedstuffs were incorporated using a cutter-mixer (model CM450, Hobart Corporation, Troy, Ohio), pelleted using a food grinder, dried at room temperature to approximately $889 \mathrm{~g} / \mathrm{kg}$ dry matter, and stored frozen $\left(-20^{\circ} \mathrm{C}\right)$ throughout the duration of the study. Proximate analyses of triplicate diet samples were conducted according to standard methods for analysis of animal feeds (Folch et al. 1957; AOAC 1995) to confirm diet 
TABLE 1.-Formulation and proximate composition of experimental feeds fed to sunshine bass. All proximate composition values are expressed as means \pm SEs $(\mathrm{g} / \mathrm{kg}$; dry matter basis).

\begin{tabular}{lccccc}
\hline \multicolumn{1}{c}{ Ingredient } & $100 \%$ Fish oil & $50 \%$ Coconut oil & $100 \%$ Coconut oil & $50 \%$ Palm oil & $100 \%$ Palm oil \\
\hline Fish meal $^{\mathrm{a}}$ & 200 & 200 & 200 & 200 & 200 \\
Fish oil $^{\mathrm{a}}$ & 98 & 49 & & 49 & \\
Coconut oil $^{\mathrm{b}}$ & & 49 & 98 & & \\
Palm oil $^{\mathrm{c}}$ & & & 49 & 49 & 98 \\
Corn gluten meal $^{\mathrm{d}}$ & 140 & 140 & 140 & 140 & 140 \\
Wheat bran $_{\text {Soybean meal }}$ & 201 & 201 & 201 & 201 & 201 \\
Carboxymethyl cellulose $_{\text {Sodium phosphate monobasic }}$ & 20 & 300 & 300 & 300 & 300 \\
Calcium phosphate dibasic & 15 & 15 & 20 & 20 & 20 \\
Choline chloride & 6 & 15 & 15 & 15 & 15 \\
Mineral premix & 1.5 & 1.5 & 6 & 6 & 6 \\
Vitamin premix & 1.5 & 1.5 & 1.5 & 1.5 & 1.5 \\
Proximate composition & & & & 1.5 & 1.5 \\
$\quad$ Dry matter & $883 \pm 1$ & $890 \pm 1$ & $893 \pm 1$ & $893 \pm 1$ & $884 \pm 1$ \\
$\quad$ Protein & $405 \pm 8$ & $409 \pm 8$ & $394 \pm 8$ & $401 \pm 8$ & $405 \pm 8$ \\
$\quad$ Lipid & $146 \pm 2$ & $151 \pm 2$ & $137 \pm 2$ & $147 \pm 2$ & $151 \pm 2$ \\
Ash & $104 \pm 1$ & $104 \pm 1$ & $104 \pm 1$ & $103 \pm 1$ & $102 \pm 1$ \\
\hline
\end{tabular}

\footnotetext{
${ }^{a}$ Derived from menhaden Brevoortia spp.; Omega Protein, Inc., Houston, Texas.

${ }^{\mathrm{b}}$ Spectrum Organic Products, Petaluma, California.

${ }^{\mathrm{c}}$ Jungle Products, Edison, New Jersey.

d Tate and Lyle, Decatur, Illinois.

${ }^{\mathrm{e}}$ Formulated to contain (per kilogram) 7,000 mg copper, 70,000 mg iron, 100,000 mg manganese, and 200,000 mg zinc, along with $0.24 \%$ iodine.

${ }^{\mathrm{f}}$ Formulated to contain (per kilogram) $99.8 \mathrm{mg}$ selenium, 2,200 mg folic acid, 88,000 mg niacin, 35,200 mg pantothenic acid, 11,000 $\mathrm{mg}$ vitamin $\mathrm{B}_{6}, 13,200 \mathrm{mg}$ riboflavin, $11,000 \mathrm{mg}$ thiamin, $11,000 \mathrm{mg}$ vitamin $\mathrm{B}_{12}, 66,000 \mathrm{mg}$ vitamin $\mathrm{E}, 4,400$ $\mathrm{mg}$ vitamin $\mathrm{K}, 4,400,000 \mathrm{IU}$ vitamin A, 2,200,000 IU vitamin D, and 100,000 $\mathrm{mg}$ vitamin C.
}

composition (Table 1). Reserved crude lipid samples were analyzed for FA composition (Table 2) according to the procedures described by Lane et al. (2006).

Experimental design and feeding trial.-Twentyfive juvenile sunshine bass $(25.4 \pm 0.1 \mathrm{~g}$ [mean \pm SE]; Keo Fish Farm, Keo, Arkansas) were stocked into each tank of a recirculation system consisting of thirty 270-L fiberglass tanks with associated mechanical and biological filtration units. Each experimental feed was randomly assigned to six replicate tanks; however, a mechanical failure resulted in the loss of one tank within the $100 \%$-CO treatment group $(N=6$ for $100 \%$ FO, $50 \%$ CO, $50 \%$ PO, and $100 \%$ PO; $N=5$ for $100 \%$ $\mathrm{CO})$. All fish were fed assigned feeds once daily to apparent satiation to simplify trial management.

Temperature, dissolved oxygen (YSI Model 55 Oxygen Meter, Yellow Springs, Ohio), ammonia-, nitrite-, and nitrate-nitrogen as well as alkalinity were measured periodically throughout the study period (Hach DR/2010 spectrophotometer, Hach Company, Loveland, Colorado). All water quality conditions were maintained within ranges suitable for sunshine bass culture (Kohler 2000). All culture and husbandry methods, as well as euthanasia and sample collection procedures described below, were conducted under the direction and approval of the Southern Illinois University Institutional Animal Care and Use Committee, protocol 07-046.
Harvest, sample collection, and production performance.-After 8 weeks, two fish were removed from each tank and immediately anesthetized in a solution of tricaine methanesulfonate (MS-222; $\sim 200 \mathrm{mg} / \mathrm{L}$ ) in culture water. Each anesthetized fish was individually weighed and euthanized by single cranial pithing before tissue sample collection. Samples of fillet tissue were taken from the fillets, packaged in sterile polyethylene bags (Whirl-pak, Nasco, Fort Atkinson, Wisconsin), and stored frozen $\left(-80^{\circ} \mathrm{C}\right)$ before proximate and FA analyses. Livers were dissected from the viscera to calculate hepatosomatic index [HSI; (liver weight/ whole body weight $\times 100$ ]. Samples of liver and intraperitoneal fat (IPF) tissue were packaged and stored in the same manner as fillet samples for FA analysis.

Average individual percent weight gain $\{[$ (average individual weight $_{\text {final }}$ - average individual weight initial $\left._{1}\right) /$ average individual weight initial $\left.\left._{1}\right] \times 100\right\}$, feed conversion ratio $[\mathrm{FCR}$, average individual dry matter (DM) consumption/average individual gain], feed intake \{FI, [total DM intake/(initial weight $\times$ final weight $\left.)^{0.5} / \mathrm{d}\right] \times$ $100\}$, and specific growth rate $\left\{\mathrm{SGR},\left[\log _{e}(\right.\right.$ final weight) $-\log _{e}$ (initial weight)]/d $\}$ were calculated for each tank. Excluding the mechanical failure resulting in the loss of one tank, no mortalities occurred during the 8-week culture period.

Fillet lipid composition.-Fillet samples were lyophilized and pulverized before lipid extraction and FA 
TABLE 2.-Fatty acid composition of experimental feeds. Abbreviations are as follows: SFA = saturated fatty acids, MUFA = monounsaturated fatty acids, PUFA = polyunsaturated fatty acids, MC-PUFA = medium-chain PUFA, and LC-PUFA = longchain PUFA (see footnotes for additional details). In the notation for individual fatty acids, the number to the left of the colon is the number of carbon atoms in the compound, the number immediately to the right of the colon is the number of double bonds, and the number after the hyphen indicates the position of the first double bond from the methyl end.

\begin{tabular}{|c|c|c|c|c|c|c|}
\hline Fatty acid(s) & $100 \%$ Fish oil & $50 \%$ Coconut oil & $100 \%$ Coconut oil & $50 \%$ Palm oil & $100 \%$ Palm oil & SE \\
\hline $8: 0$ & 0.0 & 0.6 & 1.3 & 0.0 & 0.0 & 0.1 \\
\hline 10:0 & 0.0 & 1.8 & 3.4 & 0.0 & 0.0 & 0.0 \\
\hline 12:0 & 0.2 & 18.4 & 35.3 & 0.1 & 0.2 & 0.0 \\
\hline 14:0 & 8.1 & 12.2 & 15.9 & 4.8 & 2.0 & 0.0 \\
\hline $16: 0$ & 19.7 & 16.2 & 13.5 & 29.4 & 35.6 & 0.0 \\
\hline 18:0 & 3.5 & 3.3 & 3.3 & 4.1 & 4.2 & 0.0 \\
\hline Total SFA $^{\mathrm{a}}$ & 33.1 & 53.8 & 73.3 & 39.7 & 43.0 & 0.1 \\
\hline $16: 1(n-7)$ & 10.6 & 6.1 & 1.7 & 5.7 & 1.5 & 0.0 \\
\hline $18: 1(n-7)$ & 2.9 & 1.8 & 0.7 & 1.9 & 1.0 & 0.0 \\
\hline $18: 1(n-9)$ & 9.2 & 8.9 & 9.1 & 21.1 & 34.3 & 0.0 \\
\hline Total MUFA ${ }^{\mathrm{b}}$ & 24.0 & 17.7 & 11.7 & 29.6 & 37.3 & 0.0 \\
\hline $16: 2(n-4)$ & 1.2 & 0.7 & 0.2 & 0.7 & 0.2 & 0.0 \\
\hline $16: 3(n-4)$ & 1.6 & 0.9 & 0.2 & 0.9 & 0.2 & 0.0 \\
\hline $18: 2(n-6)$ & 8.8 & 8.4 & 9.3 & 11.8 & 14.5 & 0.1 \\
\hline $20: 4(n-6)$ & 1.4 & 0.8 & 0.3 & 0.8 & 0.2 & 0.0 \\
\hline All $(n-6)^{c}$ & 10.9 & 9.7 & 9.7 & 13.0 & 14.8 & 0.1 \\
\hline $18: 3(n-3)$ & 1.6 & 1.1 & 0.7 & 1.2 & 0.8 & 0.0 \\
\hline $18: 4(n-3)$ & 2.1 & 1.2 & 0.3 & 1.1 & 0.3 & 0.0 \\
\hline $20: 4(n-3)$ & 1.2 & 0.7 & 0.2 & 0.6 & 0.1 & 0.0 \\
\hline $20: 5(n-3)$ & 12.7 & 7.2 & 1.8 & 6.7 & 1.5 & 0.0 \\
\hline $22: 5(n-3)$ & 2.5 & 1.4 & 0.3 & 1.3 & 0.3 & 0.0 \\
\hline $22: 6(n-3)$ & 8.6 & 5.1 & 1.5 & 4.8 & 1.3 & 0.0 \\
\hline All (n-3) & 28.7 & 16.9 & 4.8 & 15.9 & 4.4 & 0.0 \\
\hline Total PUFA $^{\mathrm{d}}$ & 43.0 & 28.6 & 15.0 & 30.7 & 19.7 & 0.1 \\
\hline Total LC-PUFA ${ }^{\mathrm{e}}$ & 26.6 & 15.5 & 4.1 & 14.5 & 3.6 & 0.0 \\
\hline Total MC-PUFA ${ }^{\mathrm{f}}$ & 13.4 & 11.3 & 10.4 & 14.6 & 15.7 & 0.1 \\
\hline$(n-3):(n-6)$ & 2.6 & 1.7 & 0.5 & 1.2 & 0.3 & 0.0 \\
\hline
\end{tabular}

${ }^{a}$ Sum of all fatty acids without double bonds; includes 15:0 and 17:0 in addition to the individually reported SFA.

b Sum of all fatty acids with one double bond; includes 14:1, 17:1, and 24:1(n-9) in addition to the individually reported MUFA.

${ }^{c}$ Includes 18:3(n-6), 20:2(n-6), and 20:3(n-6) in addition to the individually reported (n-6) fatty acids.

${ }^{d}$ Sum of all fatty acids with two or more double bonds; includes 18:3(n-4), 20:4(n-3), 20:2(n-6), and 20:3(n-6) in addition to the individually reported PUFA.

' Sum of all PUFA with 20 or more carbon atoms, three or more double bonds; includes 20:3(n-6) in addition to the individually reported LC-PUFA.

${ }^{\mathrm{f}}$ Sum of all PUFA with 18 carbon atoms; includes 18:3(n-6) in addition to the individually reported MC-PUFA.

analysis using the same methods as for diet samples (Lane et al. 2006). Intact liver and IPF samples were homogenized in solvent before extraction in the same manner as the other samples.

Statistical analyses.-All data were analyzed by one-way analysis of variance (ANOVA) within the general linear model framework of the Statistical Analysis System, version 9.1 (SAS Institute 2005) to determine significance of differences among dietary treatment regimes. For parameters exhibiting significant differences, means were compared using post hoc Tukey's Honest Significant Difference (HSD) tests. In all cases, differences were considered significant at $P$ $<0.05$. Regression of FA data were calculated using the regression function in Excel 2007 (Microsoft 2007).

\section{Results}

Partial replacement of FO with $\mathrm{CO}$ or PO resulted in significant alteration of fillet FA profile, and the alterations associated with $50 \%$-FO replacement were exacerbated within the $100 \%$-replacement groups (Table 3). Feeding increasing levels of $\mathrm{CO}$ resulted in increased fillet deposition of 12:0, 14:0 and total SFA, at the expense of 20:5(n-3), 22:6(n-3), and LC-PUFA. ${ }^{1}$

${ }^{1}$ In the fatty acid notation used in this paper, the number to the left of the colon is the number of carbon atoms in the compound, the number immediately to the right of the colon is the number of double bonds, and the number after the hyphen indicates the position of the first double bond from the methyl end. 
TABLE 3.- Total fatty acid composition of sunshine bass fillets. Values represent least-squares means of duplicate samples from five or more replicate tanks. Means with letters in common are not significantly different. SE values $<0.1$ are reported as 0.0 . See Table 2 for additional details.

\begin{tabular}{|c|c|c|c|c|c|c|}
\hline Fatty acid(s) & $100 \%$ Fish oil & $50 \%$ Coconut oil & $100 \%$ Coconut oil & $50 \%$ Palm oil & $100 \%$ Palm oil & $P$-value \\
\hline $12: 0$ & $0.2 \pm 0.2 \times$ & $8.8 \pm 0.2 \mathrm{y}$ & $14.6 \pm 0.2 \mathrm{z}$ & $0.1 \pm 0.2 \times$ & $0.2 \pm 0.2 \times$ & $<0.001$ \\
\hline 14:0 & $5.6 \pm 0.1 \times$ & $8.9 \pm 0.1 \mathrm{y}$ & $11.4 \pm 0.1 \mathrm{z}$ & $3.5 \pm 0.1 \mathrm{w}$ & $1.8 \pm 0.1 \mathrm{v}$ & $<0.001$ \\
\hline $16: 0$ & $20.0 \pm 0.2 \times$ & $18.6 \pm 0.2 \mathrm{w}$ & $18.2 \pm 0.2 \mathrm{w}$ & $23.0 \pm 0.2 \mathrm{y}$ & $25.1 \pm 0.2 \mathrm{z}$ & $<0.001$ \\
\hline 18:0 & $3.7 \pm 0.1 \mathrm{y}$ & $3.7 \pm 0.1 \mathrm{y}$ & $4.3 \pm 0.1 \mathrm{z}$ & $3.8 \pm 0.1 \mathrm{y}$ & $4.4 \pm 0.1 \mathrm{z}$ & $<0.001$ \\
\hline Total SFA ${ }^{\mathrm{a}}$ & $30.4 \pm 0.4 \mathrm{w}$ & $41.0 \pm 0.4 \mathrm{y}$ & $49.4 \pm 0.4 \mathrm{z}$ & $31.1 \pm 0.4 \mathrm{xw}$ & $31.9 \pm 0.4 \mathrm{x}$ & $<0.001$ \\
\hline $16: 1(n-7)$ & $9.4 \pm 0.1 \mathrm{z}$ & $6.4 \pm 0.1 \mathrm{y}$ & $3.5 \pm 0.1 \mathrm{x}$ & $6.4 \pm 0.1 \mathrm{y}$ & $3.1 \pm 0.1 \mathrm{w}$ & $<0.001$ \\
\hline $18: 1(n-7)$ & $3.3 \pm 0.0 \mathrm{z}$ & $2.3 \pm 0.0 \mathrm{y}$ & $1.3 \pm 0.0 \mathrm{x}$ & $2.3 \pm 0.0 \mathrm{y}$ & $1.4 \pm 0.0 \mathrm{x}$ & $<0.001$ \\
\hline $18: 1(n-9)$ & $12.9 \pm 0.3 \mathrm{v}$ & $14.7 \pm 0.3 \mathrm{w}$ & $19.3 \pm 0.4 \times$ & $25.2 \pm 0.3 \mathrm{y}$ & $35.4 \pm 0.3 \mathrm{z}$ & $<0.001$ \\
\hline $20: 1(n-9)$ & $1.0 \pm 0.0 \mathrm{y}$ & $0.9 \pm 0.0 \mathrm{y}$ & $1.0 \pm 0.0 \mathrm{y}$ & $1.1 \pm 0.0 \mathrm{z}$ & $1.2 \pm 0.0 \mathrm{z}$ & $<0.001$ \\
\hline Total MUFA ${ }^{\mathrm{b}}$ & $27.3 \pm 0.4 \mathrm{x}$ & $25.2 \pm 0.4 \mathrm{w}$ & $26.0 \pm 0.5 \mathrm{w}$ & $35.6 \pm 0.4 \mathrm{y}$ & $41.5 \pm 0.4 \mathrm{z}$ & $<0.001$ \\
\hline $18: 2(n-6)$ & $8.3 \pm 0.2 \mathrm{w}$ & $9.7 \pm 0.2 \times$ & $11.4 \pm 0.2 \mathrm{y}$ & $11.9 \pm 0.2 \mathrm{y}$ & $15.4 \pm 0.2 \mathrm{z}$ & $<0.001$ \\
\hline $20: 4(n-6)$ & $1.9 \pm 0.0 \mathrm{z}$ & $1.5 \pm 0.0 \mathrm{y}$ & $1.2 \pm 0.0 \mathrm{x}$ & $1.3 \pm 0.0 \mathrm{x}$ & $0.9 \pm 0.0 \mathrm{w}$ & $<0.001$ \\
\hline All $(n-6)^{c}$ & $11.4 \pm 0.2 \mathrm{w}$ & $12.4 \pm 0.2 \mathrm{x}$ & $14.3 \pm 0.2 \mathrm{y}$ & $14.3 \pm 0.2 \mathrm{y}$ & $17.5 \pm 0.2 \mathrm{z}$ & $<0.001$ \\
\hline $18: 3(n-3)$ & $1.3 \pm 0.0 \mathrm{z}$ & $1.1 \pm 0.0 \mathrm{y}$ & $0.9 \pm 0.0 \times$ & $1.1 \pm 0.0 \mathrm{y}$ & $0.8 \pm 0.0 \mathrm{x}$ & $<0.001$ \\
\hline $18: 4(n-3)$ & $1.3 \pm 0.0 \mathrm{z}$ & $0.8 \pm 0.0 \mathrm{y}$ & $0.3 \pm 0.0 \mathrm{x}$ & $0.7 \pm 0.0 \mathrm{w}$ & $0.2 \pm 0.0 \mathrm{v}$ & $<0.001$ \\
\hline $20: 4(n-3)$ & $1.0 \pm 0.0 \mathrm{z}$ & $0.7 \pm 0.0 \mathrm{y}$ & $0.3 \pm 0.0 \times$ & $0.6 \pm 0.0 \mathrm{x}$ & $0.2 \pm 0.0 \mathrm{v}$ & $<0.001$ \\
\hline $20: 5(n-3)$ & $11.0 \pm 0.1 \mathrm{z}$ & $7.5 \pm 0.1 \mathrm{y}$ & $3.5 \pm 0.2 \mathrm{w}$ & $6.7 \pm 0.2 \times$ & $2.9 \pm 0.2 \mathrm{v}$ & $<0.001$ \\
\hline $22: 5(n-3)$ & $2.9 \pm 0.0 \mathrm{z}$ & $2.1 \pm 0.0 \mathrm{y}$ & $0.9 \pm 0.0 \mathrm{w}$ & $1.7 \pm 0.0 \times$ & $0.8 \pm 0.0 \mathrm{v}$ & $<0.001$ \\
\hline $22: 6(n-3)$ & $11.1 \pm 0.2 \mathrm{z}$ & $7.6 \pm 0.2 \mathrm{y}$ & $4.0 \pm 0.2 \mathrm{w}$ & $6.8 \pm 0.2 \times$ & $3.8 \pm 0.2 \mathrm{w}$ & $<0.001$ \\
\hline All $(n-3)$ & $28.6 \pm 0.4 \mathrm{z}$ & $19.9 \pm 0.4 \mathrm{y}$ & $9.8 \pm 0.4 \mathrm{w}$ & $17.7 \pm 0.4 x$ & $8.7 \pm 0.4 \mathrm{w}$ & $<0.001$ \\
\hline Total PUFA $^{\mathrm{d}}$ & $42.2 \pm 0.5 \mathrm{z}$ & $33.8 \pm 0.5 \mathrm{y}$ & $24.6 \pm 0.5 \mathrm{w}$ & $33.2 \pm 0.5 \mathrm{y}$ & $26.6 \pm 0.5 \mathrm{x}$ & $<0.001$ \\
\hline Total LC-PUFA ${ }^{\mathrm{e}}$ & $28.2 \pm 0.4 \mathrm{z}$ & $19.7 \pm 0.4 \mathrm{y}$ & $10.1 \pm 0.5 \mathrm{w}$ & $17.3 \pm 0.4 \mathrm{x}$ & $8.8 \pm 0.4 \mathrm{v}$ & $<0.001$ \\
\hline Total MC-PUFA ${ }^{\mathrm{f}}$ & $11.7 \pm 0.2 \mathrm{v}$ & $12.3 \pm 0.2 \mathrm{w}$ & $13.2 \pm 0.2 \mathrm{x}$ & $14.3 \pm 0.2 \mathrm{y}$ & $16.9 \pm 0.2 \mathrm{z}$ & $<0.001$ \\
\hline$(n-3):(n-6)$ & $2.5 \pm 0.0 \mathrm{z}$ & $1.6 \pm 0.0 \mathrm{y}$ & $0.7 \pm 0.0 \mathrm{w}$ & $1.2 \pm 0.0 \mathrm{x}$ & $0.5 \pm 0.0 \mathrm{v}$ & $<0.001$ \\
\hline Total lipid ${ }^{\mathrm{g}}$ & $9.1 \pm 0.5 \mathrm{y}$ & $9.7 \pm 0.5 \mathrm{y}$ & $9.1 \pm 0.5 \mathrm{y}$ & $11.3 \pm 0.5 \mathrm{z}$ & $8.9 \pm 0.5 \mathrm{y}$ & 0.008 \\
\hline
\end{tabular}

${ }^{a}$ Includes 10:0, 15:0, and 17:0 in addition to the individually reported SFA.

${ }^{\mathrm{b}}$ Includes 14:1, 17:1, and 24:1(n-9) in addition to the individually reported MUFA.

${ }^{\mathrm{c}}$ Includes $18: 3(\mathrm{n}-6), 20: 2(\mathrm{n}-6)$, and 20:3(n-6) in addition to the individually reported (n-6) fatty acids.

${ }^{d}$ Includes 16:2(n-4), 16:3(n-4), 18:3(n-4), 20:4(n-3), 20:2(n-6), and 20:3(n-6) in addition to the individually reported PUFA.

${ }^{\mathrm{e}}$ Includes 20:3(n-6) in addition to the individually reported LC-PUFA.

${ }^{\mathrm{f}}$ Includes $18: 3(\mathrm{n}-4)$ and $18: 3(\mathrm{n}-6)$ in addition to the individually reported MC-PUFA.

${ }^{\mathrm{g}}$ Percent of dry matter.

Feeding PO was also associated with reductions in fillet LC-PUFA and significant enrichment of POassociated FAs within the total lipid profile, most notably 18:1(n-9) and total MUFA. Liver and IPF FA profiles were also affected by dietary FA composition (Tables 4, 5). All tissues essentially mirrored dietary composition within the $100 \%$-FO, $50 \%-\mathrm{CO}$, and $50 \%$ PO groups; however, notable deviations from dietary profile were observed in the $100 \%$-CO and $100 \%$-PO groups, particularly within the fillet and liver lipid (Figures 1, 2).

Production performance was generally within acceptable ranges for sunshine bass; however, weight gain was significantly reduced within the $100 \%-\mathrm{CO}$ group (Table 6). Food conversion ratio, FI, and SGR were not significantly affected by dietary treatment. The HSI was significantly elevated within the $100 \%$ FO replacement groups; corresponding increases in liver lipid were also observed (Table 4).

\section{Discussion}

Divergence in tissue FA profile among fish fed different lipid sources has been widely reported (Bell et al. 2001, 2002; Caballero et al. 2002; Bransden et al. 2003; Glencross et al. 2003; Wonnacott et al. 2004; Lane et al. 2006; Menoyo et al. 2007; Lewis and Kohler 2008), and in this sense, our observations of varying fillet FA composition are conventional. However, there are several noteworthy nuances in the present dataset that provide further insight. First, the magnitude of the differences between treatment groups is considerable and developed over a relatively short period of time. We evaluated the 50\%-CO formulation in a previous trial with sunshine bass (Trushenski et al. 2008a), and comparing the results of this previous study with the present work provides a useful illustration of this point. Previously, we observed significant fillet enrichment of SFAs after feeding for 20 weeks, but did not observe a significant reduction of LC-PUFA until 28 weeks had 
TABLE 5.-Total intraperitoneal fat fatty acid composition in sunshine bass. See Table 3 for additional details.

\begin{tabular}{|c|c|c|c|c|c|c|}
\hline Fatty acids & $100 \%$ Fish oil & $50 \%$ Coconut oil & $100 \%$ Coconut oil & $50 \%$ Palm oil & $100 \%$ Palm oil & $P$-value \\
\hline 12:0 & $0.3 \pm 0.4 \mathrm{x}$ & $14.0 \pm 0.4 \mathrm{y}$ & $23.2 \pm 0.4 \mathrm{z}$ & $0.1 \pm 0.4 \mathrm{x}$ & $0.2 \pm 0.4 \mathrm{x}$ & $<0.001$ \\
\hline 14:0 & $7.8 \pm 0.2 \mathrm{x}$ & $11.7 \pm 0.2 \mathrm{y}$ & $14.6 \pm 0.2 \mathrm{z}$ & $4.6 \pm 0.2 \mathrm{w}$ & $2.1 \pm 0.2 \mathrm{v}$ & $<0.001$ \\
\hline $16: 0$ & $19.6 \pm 0.2 \mathrm{x}$ & $16.6 \pm 0.2 \mathrm{w}$ & $15.9 \pm 0.2 \mathrm{v}$ & $22.8 \pm 0.2 \mathrm{y}$ & $25.8 \pm 0.2 \mathrm{z}$ & $<0.001$ \\
\hline 18:0 & $2.9 \pm 0.1 \mathrm{x}$ & $2.6 \pm 0.1 \mathrm{w}$ & $2.9 \pm 0.1 \times$ & $3.2 \pm 0.1 \mathrm{y}$ & $3.8 \pm 0.1 \mathrm{z}$ & $<0.001$ \\
\hline Total SFA ${ }^{\mathrm{a}}$ & $30.9 \pm 0.6 \mathrm{x}$ & $45.7 \pm 0.5 \mathrm{y}$ & $57.8 \pm 0.6 \mathrm{z}$ & $31.0 \pm 0.5 \mathrm{x}$ & $32.1 \pm 0.5 \mathrm{x}$ & $<0.001$ \\
\hline $16: 1(n-7)$ & $12.2 \pm 0.1 \mathrm{z}$ & $7.6 \pm 0.1 \mathrm{y}$ & $3.8 \pm 0.1 \mathrm{x}$ & $7.5 \pm 0.1 \mathrm{y}$ & $3.1 \pm 0.1 \mathrm{w}$ & $<0.001$ \\
\hline $18: 1(n-7)$ & $3.7 \pm 0.0 \mathrm{z}$ & $2.4 \pm 0.0 \mathrm{x}$ & $1.4 \pm 0.0 \mathrm{v}$ & $2.5 \pm 0.0 \mathrm{y}$ & $1.5 \pm 0.0 \mathrm{w}$ & $<0.001$ \\
\hline $18: 1(n-9)$ & $15.0 \pm 0.5 \mathrm{v}$ & $16.4 \pm 0.5 \mathrm{w}$ & $20.4 \pm 0.5 \mathrm{x}$ & $29.3 \pm 0.5 \mathrm{y}$ & $41.3 \pm 0.5 \mathrm{z}$ & $<0.001$ \\
\hline 20:1(n-9) & $1.3 \pm 0.0 \mathrm{z}$ & $1.0 \pm 0.0 \mathrm{y}$ & $1.0 \pm 0.0 \mathrm{y}$ & $1.3 \pm 0.0 \mathrm{z}$ & $1.3 \pm 0.0 \mathrm{z}$ & $<0.001$ \\
\hline Total MUFA ${ }^{\mathrm{b}}$ & $32.4 \pm 0.5 \times$ & $27.7 \pm 0.5 \mathrm{w}$ & $26.7 \pm 0.5 \mathrm{w}$ & $40.8 \pm 0.5 y$ & $47.3 \pm 0.5 \mathrm{z}$ & $<0.001$ \\
\hline $18: 2(n-6)$ & $10.2 \pm 0.2 \mathrm{w}$ & $10.8 \pm 0.1 \mathrm{x}$ & $9.9 \pm 0.2 \mathrm{w}$ & $13.7 \pm 0.1 \mathrm{y}$ & $15.8 \pm 0.1 \mathrm{z}$ & $<0.001$ \\
\hline $20: 4(n-6)$ & $1.1 \pm .0 \mathrm{z}$ & $0.6 \pm 0.0 \mathrm{y}$ & $0.3 \pm 0.0 \times$ & $0.6 \pm 0.0 \mathrm{y}$ & $0.2 \pm 0.0 \mathrm{w}$ & $<0.001$ \\
\hline All $(n-6)^{c}$ & $12.6 \pm 0.2 \times$ & $12.6 \pm 0.1 \mathrm{x}$ & $11.5 \pm 0.2 \mathrm{w}$ & $15.4 \pm 0.1 \mathrm{y}$ & $16.9 \pm 0.2 \mathrm{z}$ & $<0.001$ \\
\hline $18: 3(n-3)$ & $1.7 \pm 0.0 \mathrm{z}$ & $1.3 \pm 0.0 \mathrm{y}$ & $0.9 \pm 0.0 \mathrm{x}$ & $1.3 \pm 0.0 \mathrm{y}$ & $0.9 \pm 0.0 \mathrm{x}$ & $<0.001$ \\
\hline $18: 4(n-3)$ & $1.7 \pm 0.0 \mathrm{z}$ & $1.0 \pm 0.0 \mathrm{y}$ & $0.3 \pm 0.0 \mathrm{w}$ & $0.9 \pm 0.0 \mathrm{x}$ & $0.2 \pm 0.0 \mathrm{v}$ & $<0.001$ \\
\hline $20: 4(n-3)$ & $1.2 \pm 0.0 \mathrm{z}$ & $0.8 \pm 0.0 \mathrm{y}$ & $0.2 \pm 0.0 \mathrm{w}$ & $0.7 \pm 0.0 \mathrm{x}$ & $0.2 \pm 0.0 \mathrm{w}$ & $<0.001$ \\
\hline $20: 5(n-3)$ & $9.8 \pm 0.2 \mathrm{z}$ & $5.2 \pm 0.1 \mathrm{y}$ & $1.2 \pm 0.2 \mathrm{x}$ & $4.9 \pm 0.1 \mathrm{y}$ & $1.1 \pm 0.1 \mathrm{x}$ & $<0.001$ \\
\hline $22: 5(n-3)$ & $2.8 \pm 0.0 \mathrm{z}$ & $1.8 \pm 0.0 \mathrm{y}$ & $0.4 \pm 0.0 \mathrm{w}$ & $1.5 \pm 0.0 \mathrm{x}$ & $0.4 \pm 0.0 \mathrm{w}$ & $<0.001$ \\
\hline $22: 6(n-3)$ & $6.4 \pm 0.1 \mathrm{z}$ & $3.4 \pm 0.1 \mathrm{y}$ & $0.8 \pm 0.1 \times$ & $3.2 \pm 0.1 \mathrm{y}$ & $0.8 \pm 0.1 \times$ & $<0.001$ \\
\hline All (n-3) & $20.3 \pm 0.3 \mathrm{z}$ & $11.3 \pm 0.3 \mathrm{y}$ & $2.7 \pm 0.3 \mathrm{w}$ & $10.4 \pm 0.3 \mathrm{x}$ & $2.4 \pm 0.3 \mathrm{w}$ & $<0.001$ \\
\hline Total PUFA $^{\mathrm{d}}$ & $36.8 \pm 0.4 \mathrm{z}$ & $26.6 \pm 0.4 x$ & $15.5 \pm 0.4 \mathrm{v}$ & $28.3 \pm 0.4 \mathrm{y}$ & $20.6 \pm 0.4 \mathrm{w}$ & $<0.001$ \\
\hline Total LC-PUFA ${ }^{\mathrm{e}}$ & $21.7 \pm 0.3 \mathrm{z}$ & $12.1 \pm 0.3 \mathrm{y}$ & $3.1 \pm 0.3 \mathrm{w}$ & $11.1 \pm 0.3 \mathrm{x}$ & $2.7 \pm 0.3 \mathrm{w}$ & $<0.001$ \\
\hline Total MC-PUFA ${ }^{\mathrm{f}}$ & $14.4 \pm 0.2 \mathrm{x}$ & $13.8 \pm 0.2 \mathrm{w}$ & $11.6 \pm 0.2 \mathrm{v}$ & $16.4 \pm 0.2 \mathrm{y}$ & $17.3 \pm 0.2 \mathrm{z}$ & $<0.001$ \\
\hline$(n-3):(n-6)$ & $1.6 \pm 0.0 \mathrm{z}$ & $0.9 \pm 0.0 \mathrm{y}$ & $0.2 \pm 0.0 \mathrm{w}$ & $0.7 \pm 0.0 \mathrm{x}$ & $0.1 \pm 0.0 \mathrm{v}$ & $<0.001$ \\
\hline
\end{tabular}

${ }^{a}$ Includes 10:0, 15:0, and 17:0 in addition to the individually reported SFA.

${ }^{\mathrm{b}}$ Includes $14: 1,17: 1$, and 24:1(n-9) in addition to the individually reported MUFA.

${ }^{c}$ Includes 18:3(n-6), 20:2(n-6), and 20:3(n-6) in addition to the individually reported (n-6) fatty acids.

${ }^{d}$ Includes 16:2(n-4), 16:3(n-4), 18:3(n-4), 20:4(n-3), 20:2(n-6), and 20:3(n-6) in addition to the individually reported PUFA.

e Includes 20:3(n-6) in addition to the individually reported LC-PUFA.

${ }^{\mathrm{f}}$ Includes 18:3(n-4) and 18:3(n-6) in addition to the individually reported MC-PUFA.

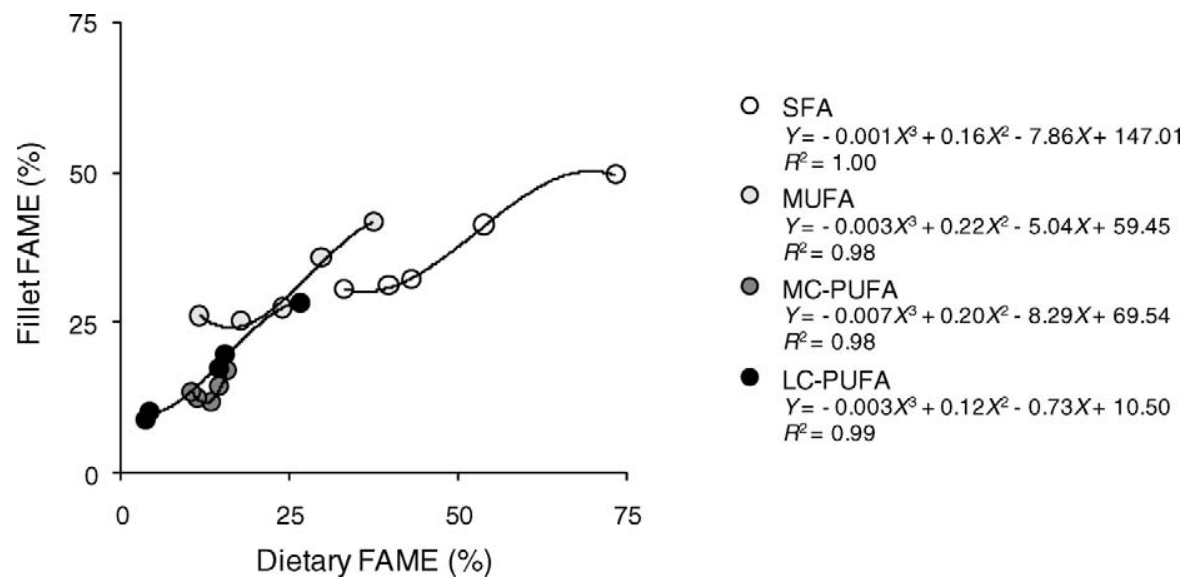

FIGURE 1.-Relationships between dietary and fillet fatty acid composition in sunshine bass (expressed as the relative percentages of fatty acid methyl esters [FAMEs]) for saturated fatty acids (SFA), monounsaturated fatty acids (MUFA), mediumchain polyunsaturated fatty acids (MC-PUFA), and long-chain polyunsaturated fatty acids (LC-PUFA). The data points are the mean compositional values reported in Tables 2 and 3; the trend lines represent third-order polynomial regressions fitted to the mean values. 
$\rightarrow$ Fillet

$\multimap$ Liver

$\multimap$ Intraperitoneal Fat

- Line of Equality

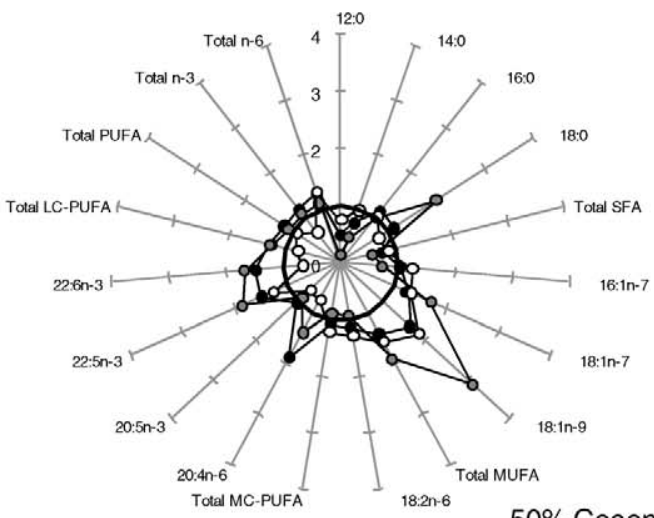

$50 \%$ Coconut Oil

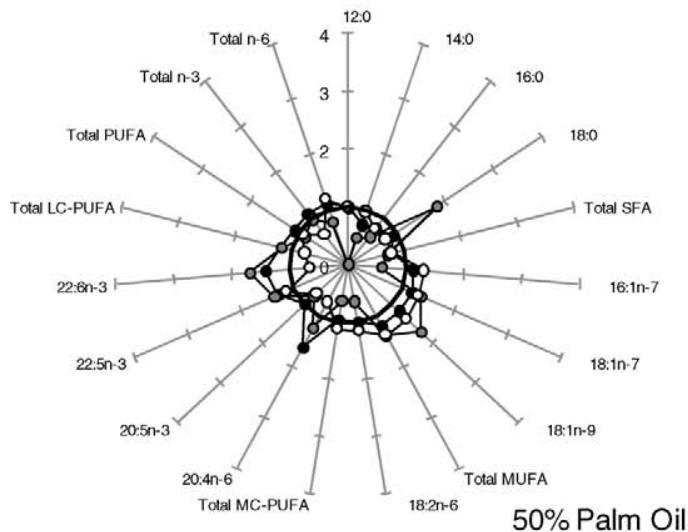

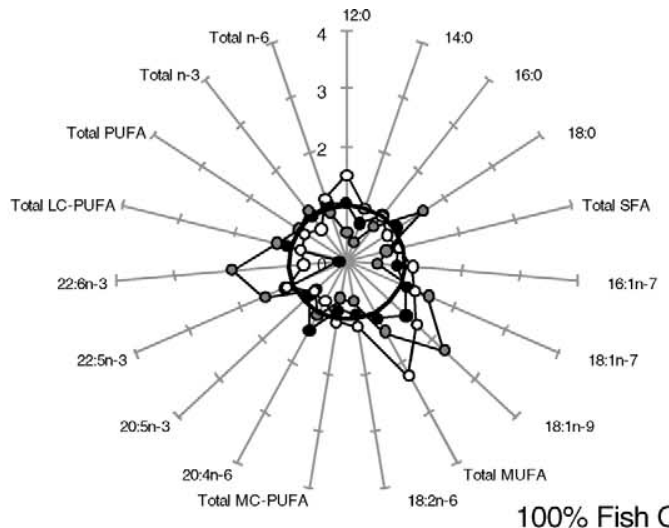

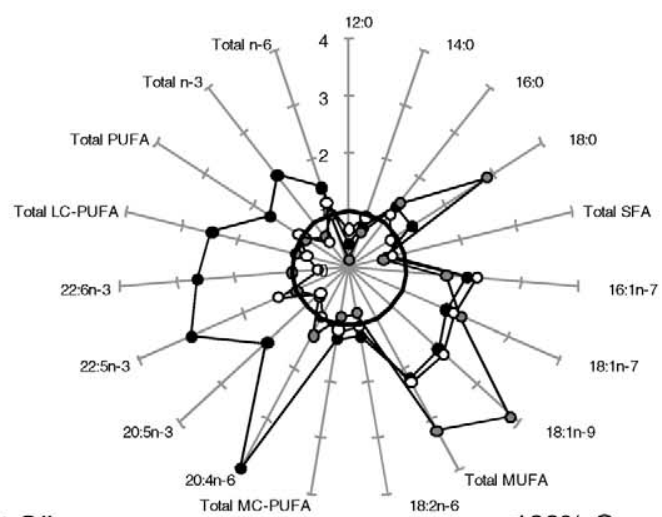

$100 \%$ Coconut Oil

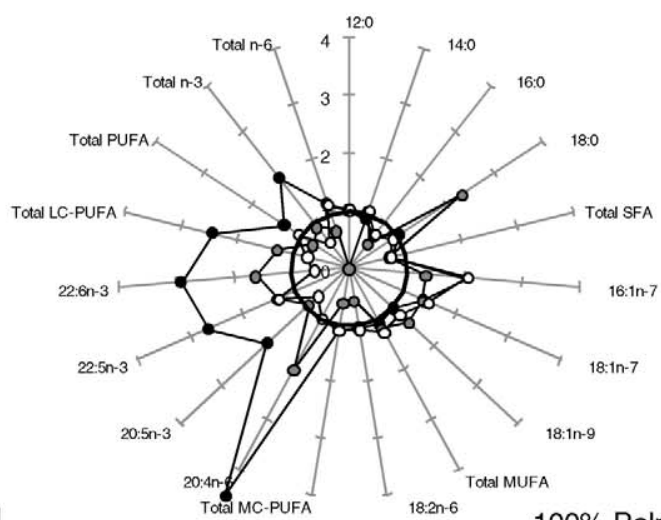

$100 \%$ Palm Oil

FIGURE 2.-Fatty acid composition of the tissue total lipid of sunshine bass expressed as a fraction of the dietary fatty acid composition (a value of 1 represents equality between the tissue and dietary composition).

growth to occur primarily via dilution processes (accumulation of TAG), whereas a FA profile change during slower (hyperplastic growth) may be largely determined by selective processes (synthesis and remodeling of PL). Although there is no data in the literature that directly support this hypothesis, some anecdotal information appears to suggest this may be the case. Haugen et al. (2006) monitored fillet FA profile change of Atlantic halibut Hippoglossus hippoglossus fed marine-derived or soy-derived oils and cultured under constant temperature and light (faster growth rate) or ambient seasonal conditions (slower growth rate). Although those authors did not address growth rate as a covarying or contributing factor, the 
TABLE 6.-Production performance of sunshine bass by dietary treatment group. Within rows, means followed by different letters are significantly different.

\begin{tabular}{lcccccr}
\hline Production variable & $100 \%$ Fish oil & $50 \%$ Coconut oil & $100 \%$ Coconut oil & $50 \%$ Palm oil & $100 \%$ Palm oil & $P$-value \\
\hline${\text { Initial weight }(\mathrm{g})^{\mathrm{a}}}^{\mathrm{b}}$ & $25.4 \pm 0.3$ & $26.0 \pm 0.3$ & $25.0 \pm 0.3$ & $25.0 \pm 0.3$ & $25.4 \pm 0.3$ & 0.198 \\
${\text { Final weight }(\mathrm{g})^{\mathrm{b}}}^{\mathrm{b}}$ & $127 \pm 7 \mathrm{z}$ & $120 \pm 7 \mathrm{z}$ & $96 \pm 8 \mathrm{y}$ & $127 \pm 7 \mathrm{z}$ & $114 \pm 7 \mathrm{zy}$ & 0.038 \\
Weight gain $(\%)^{\mathrm{bc}}$ & $402 \pm 28 \mathrm{z}$ & $362 \pm 28 \mathrm{z}$ & $284 \pm 31 \mathrm{y}$ & $408 \pm 28 \mathrm{z}$ & $349 \pm 28 \mathrm{zy}$ & 0.049 \\
Feed intake $^{\mathrm{ad}}$ & $3.5 \pm 0.2$ & $3.6 \pm 0.2$ & $3.6 \pm 0.2$ & $3.7 \pm 0.2$ & $4.2 \pm 0.2$ & 0.103 \\
Feed conversion ratio $^{\text {be }}$ & $1.1 \pm 0.1$ & $1.2 \pm 0.1$ & $1.4 \pm 0.1$ & $1.2 \pm 0.1$ & $1.4 \pm 0.1$ & 0.215 \\
Specific growth rate $^{\mathrm{bf}}$ & $2.8 \pm 0.1$ & $2.7 \pm 0.1$ & $2.4 \pm 0.1$ & $2.9 \pm 0.1$ & $2.7 \pm 0.1$ & 0.052 \\
Hepatosomatic index $^{\mathrm{bg}}$ & $1.4 \pm 0.1 \mathrm{y}$ & $1.6 \pm 0.1 \mathrm{y}$ & $2.4 \pm 0.1 \mathrm{z}$ & $1.6 \pm 0.1 \mathrm{y}$ & $2.1 \pm 0.1 \mathrm{z}$ & $<0.001$ \\
\hline
\end{tabular}

${ }^{a}$ Values represent least-squares means \pm SEs of average individual performance criteria of five or more replicate tanks.

${ }^{\mathrm{b}}$ Values represent least-squares means \pm SEs of duplicate individuals from five or more replicate tanks.

${ }^{\mathrm{c}}[$ (final weight - initial weight $) /$ initial weight $] \times 100$.

${ }^{d}$ [total dry matter intake/(initial weight $\times$ final weight) ${ }^{0.5} /$ number of days fed] $\times 100$.

${ }^{\mathrm{e}}$ Consumption/weight gain.

${ }_{[}^{\mathrm{f}}\left[\log _{10}\right.$ (final weight) $-\log _{10}$ (initial weight) $] / \mathrm{d}$.

${ }^{\mathrm{g}}$ (liver mass/whole-body mass) $\times 100$.

mean fillet composition data seem to suggest that 18:2(n-6) content (FA composition of the two experimental feeds differed most greatly with respect to $18: 2[\mathrm{n}-6]$ content) changed more rapidly among slow-growing fish within the PL fraction, whereas among fast-growing fish, the rate of change was greater within the TAG fraction. Again, this suggests that overall fillet FA profile of fast-growing fish is more strongly influenced by accumulation of neutral lipid and, therefore, less subject to the processes of selective FA metabolism. This hypothesis would explain the rapid FA profile change we observed in the present work relative to our previous study; however, additional research is needed to verify the influence of growth rate on FA profile change in fishes.

Although fillet FA profile divergence in the present work may have been largely driven by nonselective processes due to rapid growth, there appears to have been some distinction between FA classes in terms of fillet deposition. As our laboratory has previously demonstrated (Trushenski et al. 2008a), LC-PUFA were disproportionately enriched in fillets of sunshine bass fed the reduced or FO-free feeds (Figure 2). A direct linear relationship between dietary FA composition and fillet FA composition is often reported as an indicator of FA dilution. In the present study, thirdorder polynomial regressions were much more representative of the feed-fillet relationships than simple linear regressions $\left(R^{2}\right.$ values ranged from 0.98 to 1.00 , Figure 1). For SFA, MUFA, and LC-PUFA, there appeared to be a threshold of dietary influence (i.e., the fillet FA content mirrored the dietary content up to a certain point, beyond which increasing dietary levels did not result in commensurate changes in the fillet). A similar threshold was not observed for MC-PUFA; however, our feeds did not vary considerably in MCPUFA content, and it is likely that the range of dietary levels was simply insufficient to identify a breakpoint in the feed-fillet relationship for this FA class. Nonetheless, it is interesting to note the slope of the linear segment of the regressions appears to be greatest for MC-PUFA, suggesting these FAs may be able to "outcompete" other FAs for deposition in fish tissues (Bell et al. 1996; Hvattum et al. 2000; Trushenski et al. 2008a, 2008b).

Palm oil is well utilized by a wide variety of aquatic species as an alternative to fish oil (Al-Owafeir and Belal 1996; Ng et al. 2000; Lim et al. 2001; Bell et al. 2002; Ng 2002; Ng et al. 2003, 2004, 2007; FonsecaMadrigal et al. 2005; Bahurmiz and $\mathrm{Ng}$ 2007). Reductions in consumption and growth performance have not been routinely reported for fish raised on feeds based on palm oil ( $\mathrm{Ng}$ 2002), although a decreased digestibility of SFA has been noted at cooler culture temperatures and higher dietary palm-oil inclusion rates ( $\mathrm{Ng}$ et al. 2004, 2007). Coconut oil has not been as widely researched in aquaculture nutrition, but has been used successfully in feeding aquatic livestock (Alava 1998; Fontagné et al. 1999) and, based on its FA composition, should be readily digested and absorbed (Olsen et al. 1998). Craig and Gatlin (1995) noted that red drum Sciaenops ocellatus were quite effective in utilizing $\mathrm{CO}$ as a dietary lipid source, but only if minimum essential fatty acid (EFA) requirements were met. Complete replacement of FO with $\mathrm{CO}$ (in feeds based on solvent-extracted fish meal) significantly reduced weight gain; however, when CObased feeds were supplemented with $2 \%$ FO or $1 \%$ (n3) HUFA blend, production performance was either unaffected or improved (Craig and Gatlin 1995). It is possible that our feeds, based on $20 \%$ full-fat fish meal, were insufficient to meet the minimum dietary requirements of sunshine bass. Using the same basal formulation, Lewis and Kohler (2008) noted reduced 
growth in sunshine bass when more than $60 \%$ of dietary FO was replaced with canola oil, and suggested EFA content as a limiting factor. However, one would expect the $100 \%$ PO to have yielded similar results if an EFA deficiency were solely to blame. It is perhaps most likely that the impaired performance observed in the $100 \%-\mathrm{CO}$ group was a consequence of increased metabolic costs or PL deficiency.

Although SFA appear to be adequate, perhaps preferred, substrates for energy production in fishes (Henderson and Sargent 1985; Kiessling and Kiessling 1993; Henderson 1996; Froyland et al. 2000), provision of SFA also induces increased elongation and desaturation activity (Bell et al. 2002). Growth was reduced among channel catfish Ictalurus punctatus fed $\mathrm{CO}$, but excellent growth was observed among those fed beef tallow (Stickney and Andrews 1972). Those authors concluded medium-chain SFA and MUFA (beef tallow) are effectively utilized by this species, whereas shorterchain SFA (CO) are not; however, total carcass lipid did not vary between these groups, suggesting equivalent uptake of either lipid source. It is perhaps more likely that shorter-chain SFA were being biotransformed, incurring additional metabolic costs, and reducing the total availability of energy for somatic growth. Supporting this hypothesis, the predominant FAs in the CO feed, 12:0 and 14:0, were not commensurately represented within the liver lipid (primary site of FA biosynthesis and transformation), whereas 16:0, 18:0, and 18:1(n-9) were enriched relative to the diet (Stickney and Andrews 1972). Although reductions in growth performance were not observed, Caballero et al. (2002) reported similar increases in elongation-desaturation products in livers of rainbow trout Oncorhynchus mykiss fed diets containing increased levels of SFA and MUFA. In the present study, the $100 \%$-FO treatment and both $50 \%$-FO replacement treatments exhibited tissue FA profiles largely representative of dietary composition; however, complete replacement of FO resulted in considerable deviations from dietary profile. Within the livers of fish fed the $100 \%-\mathrm{CO}$ and $100 \%$ PO feeds, 18:0 and 18:1(n-9) were enriched relative to the diet whereas 12:0, 14:0, and 16:0 were notably reduced or absent (Figure 2). Again, these data seem to suggest elongation and desaturation of surplus dietary SFA within the hepatic tissue. Although sunshine bass are generally considered incapable of synthesizing LCPUFA in meaningful amounts, as vertebrates, they are undoubtedly able to produce longer-chain SFA and 18:1(n-9) from their precursors. However, additional research is needed to confirm increased FA biotransformation among sunshine bass fed SFA-rich feeds and to address whether this may affect energy balance and growth.
Depending on the extraction process used, PO contains 20-2,000 $\mu \mathrm{g} / \mathrm{L}$ PL, whereas the polar lipid content of CO is negligible (Gunstone et al. 1994). As noted by Tocher (2003), many freshwater fish species lack the ability to synthesis PL. Give the limited biosynthetic capacity of sunshine bass with respect to FA biotransformation, it is reasonable to assume that this hybrid species is also unable to meet PL requirements endogenously. Although Sealey et al. (2001) demonstrated growth performance of sunshine bass was unaffected by dietary supplementation with soy lecithin (as a source of phosphatidylcholine), the basal diet contained approximately 7\%-PL-rich FO, and was probably sufficient to meet the PL requirement of these fish without the addition of lecithin. Although the PL requirement may be lower among juvenile and subadult individuals compared with larval fish (Tocher et al. 2008), sunshine bass undoubtedly exhibit some nominal requirement for PL throughout their life cycle. Unfortunately, few studies have evaluated the PL requirements of fish beyond the early juvenile stages, and none have addressed this question in the context of sunshine bass nutrition. Although some alternative lipid sources provide considerable amounts of PL (e.g., soybean- and canola-derived feedstuffs), others may be limited or wholly deficient with respect to this nutrient (Tocher et al. 2008). Additional research is needed to establish the PL requirement of sunshine bass (and other species) at the juvenile and subadult stages to assess the potential for PL deficiency in alternative lipid-based aquafeeds.

Based on the production performance and tissue FA profiles observed in the present study, $\mathrm{CO}$ and $\mathrm{PO}$ appear to have promise as alternatives to FO in feeds for sunshine bass. However, the extent to which these alternative lipids can be implemented in aquafeeds will depend on the ability of nutritionists to resolve issues of digestibility and utilization associated with these feedstuffs and to determine the effect FO replacement may have on bioenergetics of cultured fishes.

\section{Acknowledgments}

My sincere thanks to John Boesenberg for conducting the feeding trial described herein, and to Andrew Coursey, Brian Gause, Jerome Laporte, and Heidi Lewis for assisting in sample collection and processing. I also thank Omega Protein, and Tate and Lyle for the donation of feedstuffs used in the present work.

\section{References}

Alava, V. R. 1998. Effect of salinity, dietary lipid source, and level on growth of milkfish (Chanos chanos) fry. Aquaculture 167:229-236.

Al-Owafeir, M. A., and E. H. Belal. 1996. Replacing palm oil 
for soybean oil in tilapia, Oreochromis niloticus (L.), feed. Aquaculture Research 27:221-224.

Bahurmiz, O. M., and W.-K. Ng. 2007. Effects of dietary palm oil source on growth, tissue fatty acid composition, and nutrient digestibility of red hybrid tilapia, Oreochromis sp., raised from stocking to marketable size. Aquaculture 262:382-392.

Bell, J. G., I. Ashton, C. J. Secombes, B. R. Weitzel, and J. R. Dick. 1996. Dietary lipid affects phospholipids, fatty acid compositions, eicosanoid production, and immune function in Atlantic salmon (Salmo salar). Prostaglandins, Leukotrienes, and Essential Fatty Acids 54:173-182.

Bell, J. G., R. J. Henderson, D. R. Tocher, F. McGhee, J. R. Dick, A. Porter, R. P. Smullen, and J. R. Sargent. 2002. Substituting fish oil with crude palm oil in the diet of Atlantic salmon (Salmo salar) affects muscle fatty acid composition and hepatic fatty acid metabolism. Journal of Nutrition 132:222-230.

Bell, J. G., J. McEvoy, D. R. Tocher, F. McGhee, P. J. Campbell, and J. R. Sargent. 2001. Replacement of fish oil with rapeseed oil in diets of Atlantic salmon (Salmo salar) affects tissue lipid compositions and hepatocyte fatty acid metabolism. Journal of Nutrition 131:15351543.

Bransden, M. P., C. G. Carter, and P. D. Nichols. 2003. Replacement of fish oil with sunflower oil in feeds for Atlantic salmon (Salmo salar L.): effect on growth performance, tissue fatty acid composition, and disease resistance. Comparative Biochemistry and Physiology 135B:611-625.

Caballero, M. J., A. Obach, G. Rosenlund, D. Montero, M. Gisvold, and M. S. Izquierdo. 2002. Impact of different dietary lipid sources on growth, lipid digestibility, tissue fatty acid composition, and histology of rainbow trout, Oncorhynchus mykiss. Aquaculture 214:253-271.

Craig, S. R., and D. M. Gatlin. 1995. Coconut oil and beef tallow, but not tricaprylin, can replace menhaden oil in the diet of red drum (Sciaenops ocellatus) without adversely affecting growth or fatty acid composition. Journal of Nutrition 125:3041-3048.

Dumas, A., C. F. M. de Lange, J. France, and D. P. Bureau. 2007. Quantitative description of body composition and rates of nutrient deposition in rainbow trout (Oncorhynchus mykiss). Aquaculture 273:165-181.

Folch, J., M. Lees, and G. H. Sloane-Stanley. 1957. A simple method for the isolation and purification of total lipids from animal tissues. Journal of Biological Chemistry 276:497-507.

Fonseca-Madrigal, J., V. Karalazos, P. J. Campbell, J. G. Bell, and D. R. Tocher. 2005. Influence of dietary palm oil on growth, tissue fatty acid compositions, and fatty acid metabolism in liver and intestine in rainbow trout (Oncorhynchus mykiss). Aquaculture Nutrition 11:241240.

Fontagné, S., T. Pruszynski, G. Corraze, and P. Bergot. 1999. Effect of coconut oil and tricaprylin vs. triolein on survival, growth, and fatty acid composition of common carp (Cyprinus carpio L.) larvae. Aquaculture 179:241251

Frøyland, L., Ø. Lie, and R. K. Berge. 2000. Mitochondrial and peroxisomal $\beta$-oxidation capacities in various tissues from Atlantic salmon, Salmo salar. Aquaculture Nutrition 6:85-89.

Glencross, B. D., W. E. Hawkins, and J. G. Curnow. 2003. Restoration of the fatty acid composition of red seabream (Pagrus auratus) using a fish oil finishing diet after grow-out on plant oil based diets. Aquaculture Nutrition 9:409-418.

Gunstone, F. D., J. L. Harwood, and F. B. Padley. 1994. The lipid handbook, 2nd edition. CRC Press, Boca Raton, Florida.

Haugen, T., A. Kiessling, R. E. Olsen, M. B. Røra, E. Slinde, and R. Nortredt. 2006. Seasonal variations in muscle growth dynamics and selected quality attributes in Atlantic halibut (Hippoglossus hippoglossus L.) fed dietary lipids containing soybean and/or herring oil under different rearing regimes. Aquaculture 261:565579.

Henderson, R. J. 1996. Fatty acid metabolism in freshwater fish with particular reference to polyunsaturated fatty acids. Archives of Animal Nutrition 49:5-22.

Henderson, R. J., and J. R. Sargent. 1985. Chain length specificities of mitochondrial and peroxisomal $\beta$-oxidation of fatty acids in livers of rainbow trout (Salmo gairdneri). Comparative Biochemistry and Physiology 82B:79-85.

Hvattum, E., C. Rǿsjǿ, T. Gjǿen, G. Rosenlund, and B. Ruyter. 2000. Effect of soybean oil and fish oil on individual molecular species of Atlantic salmon head kidney phosphoplipids determined by normal-phase liquid chromatography coupled to negative ion electrospray tandem mass spectrometry. Journal of Chromatography B 748:137-149.

Jobling, M. 2003. Do changes in Atlantic salmon, Salmo salar L., fillet fatty acids following a dietary switch represent wash-out or dilution? Test of a dilution model and its application. Aquaculture Research 34:1215-1221.

Jobling, M. 2004a. Are modifications in tissue fatty acid profiles following a change in diet the result of dilution? Test of a simple dilution model. Aquaculture 232:551562.

Jobling, M. 2004b. "Finishing" feeds for carnivorous fish and the fatty acid dilution model. Aquaculture Research 35:706-709.

Kiessling, K.-H., and A. Kiessling. 1993. Selective utilization of fatty acids in rainbow trout (Oncorhynchus mykiss, Walbaum) red muscle mitochondria. Canadian Journal of Zoology 71:248-251.

Kohler, C. C. 2000. Striped bass and hybrid striped bass culture. Pages 898-907 in R. R. Stickney, editor. Encyclopedia of aquaculture. Wiley, New York.

Koumans, J. T. M., and H. A. Akster. 1995. Myogenic cells in development and growth of fish. Comparative Biochemistry and Physiology 110A:3-20.

Lane, R. L., J. T. Trushenski, and C. C. Kohler. 2006. Modification of fillet composition and evidence of differential fatty acid turnover in sunshine bass Morone chrysops $\times$ M. saxatilis following change in dietary lipid source. Lipids 41:1029-1038.

Lewis, H. A., and C. C. Kohler. 2008. Minimizing fish oil and fish meal with plant-based alternatives in sunshine bass diets without negatively impacting growth and fillet fatty 
acid profile. Journal of the World Aquaculture Society 39:573-585.

Lim, P.-K., P.-L. Boey, and W.-K. Ng. 2001. Dietary palm oil level affects growth performance, protein retention, and tissue vitamin E concentration of African catfish, Clarias gariepinus. Aquaculture 202:101-112.

Menoyo, D., C. J. Lopez-Bote, A. Diez, A. Obach, and J. M. Bautista. 2007. Impact of (n-3) fatty acid chain length and $\mathrm{n}-3 / \mathrm{n}-6$ ratio in Atlantic salmon (Salmo salar) diets. Aquaculture 267:248-259.

Microsoft. 2007. Excel 2007. Microsoft, Redmond, Washington.

Ng, W.-K. 2002. Potential of palm oil utilisation in aquaculture feeds. Asia Pacific Journal of Clinical Nutrition 11:S473-S476.

Ng, W.-K., P.-K. Lim, and P.-L. Boey. 2003. Dietary lipid and palm oil source affects growth, fatty acid composition, and muscle $\alpha$-tocopherol concentration of African catfish, Clarias gariepinus. Aquaculture 215:229-243.

Ng, W.-K., T. Sigholt, and J. G. Bell. 2004. The influence of environmental temperature on the apparent nutrient and fatty acid digestibility in Atlantic salmon (Salmo salar L.) fed finishing diets containing different blends of fish oil, rapeseed oil, and palm oil. Aquaculture Research 35:1228-1237.

Ng, W.-K., M.-C. Tee, and P.-L. Boey. 2000. Evaluation of crude palm oil and refined palm olein as dietary lipids in pelleted feeds for a tropical bagrid catfish Mystus nemurus (Cuvier and Valenciennes). Aquaculture Research 31:337-347.

Ng, W.-K., D. R. Tocher, and J. G. Bell. 2007. The use of palm oil in aquaculture feeds for salmonid species. European Journal of Lipid Science and Technology 109:394-399.

Olsen, R. E., R. J. Henderson, and E. Ringǿ. 1998. The digestion and selective absorption of dietary fatty acids in
Arctic charr, Salvelinus alpines. Aquaculture Nutrition 4:13-21.

Robin, J. H., C. Regost, J. Arzel, and S. J. Kaushik. 2003. Fatty acid profile of fish following a change in dietary fatty acid source: model of fatty acid composition with a dilution hypothesis. Aquaculture 225:283-293.

SAS Institute. 2005. Statistical Analysis System, version 9.1. SAS Institute, Cary, North Carolina.

Sealey, W. M., S. R. Craig, and D. M. Gatlin. 2001. Dietary cholesterol and lecithin have limited effects on growth and body composition of hybrid striped bass (Morone chrysops $\times$ M. saxatilis). Aquaculture Nutrition 7:25-31.

Stickney, R. R., and J. W. Andrews. 1972. Effects of dietary lipids on growth, food conversion, lipid, and fatty acid composition of channel catfish. Journal of Nutrition 102:249-258

Tocher, D. R. 2003. Metabolism and functions of lipids and fatty acids in teleost fish. Reviews in Fisheries Science 11:107-184.

Tocher, D. R., E. Å Bendiksen, P. J. Campbell, and J. G. Bell. 2008. The role of phospholipids in nutrition and metabolism of teleost fish. Aquaculture 280:21-34.

Trushenski, J. T., J. Boesenberg, and C. C. Kohler. 2009. Influence of grow-out feed fatty acid composition on finishing success in Nile tilapia. North American Journal of Aquaculture 71:242-251.

Trushenski, J. T., H. A. Lewis, and C. C. Kohler. 2008a. Fatty acid profile of sunshine bass, I. Profile change is affected by initial composition and differs among tissues. Lipids 43:629-641.

Trushenski, J. T., H. A. Lewis, and C. C. Kohler. 2008b. Fatty acid profile of sunshine bass, II. Profile change differs among fillet lipid classes. Lipids 43:643-653.

Wonnacott, E. J., R. L. Lane, and C. C. Kohler. 2004. Influence of dietary replacement of menhaden oil with canola oil on fatty acid composition of sunshine bass. North American Journal of Aquaculture 66:243-250. 